\title{
Dietary resilience in patients with severe COPD at the start of a pulmonary rehabilitation program
}

This article was published in the following Dove Press journal:

International Journal of COPD

\author{
Lies ter Beek ${ }^{1-3}$ \\ Hester van der Vaart ${ }^{2}$ \\ Johan B Wempe ${ }^{2}$ \\ Aliaksandra $\bigcirc$ Dzialendzik ${ }^{4}$ \\ Jan LN Roodenburg ${ }^{3}$ \\ Cees $P$ van der Schans ${ }^{1,5,6}$ \\ Heather $\mathrm{H}$ Keller ${ }^{7,8}$ \\ Harriët Jager-Wittenaar ${ }^{1,3}$ \\ 'Hanze University of Applied Sciences, \\ Research Group Healthy Ageing, Allied \\ Health Care and Nursing, Groningen, \\ the Netherlands; ${ }^{2}$ University of \\ Groningen, University Medical \\ Center Groningen, Department of \\ Pulmonary Diseases and Tuberculosis, \\ Center for Rehabilitation, Groningen, \\ the Netherlands; ${ }^{3}$ University of \\ Groningen, University Medical \\ Center Groningen, Department of \\ Maxillofacial Surgery, Groningen, \\ the Netherlands; ${ }^{4}$ Hanze University \\ of Applied Sciences, Department of \\ Applied Psychology, Groningen, the \\ Netherlands; ${ }^{5}$ University of Groningen, \\ University Medical Center Groningen, \\ Department of Rehabilitation \\ Medicine, Groningen, the Netherlands; \\ 'University of Groningen, University \\ Medical Center Groningen, Health \\ Psychology Research, Groningen, the \\ Netherlands; ${ }^{7}$ University of Waterloo, \\ Schlegel Research Institute for Aging, \\ Waterloo, ON, Canada; ${ }^{8}$ University \\ of Waterloo, Department of \\ Kinesiology, Waterloo, ON, Canada
}

Correspondence: Lies ter Beek Hanze University of Applied Sciences, Research Group Healthy Ageing, Allied Health Care and Nursing, Petrus Driessenstraat 3, 97/4 CA Groningen, the Netherlands

Tel +3 I 50595277 |

Email l.ter.beek@pl.hanze.nl
Background: COPD may impact food-related activities, such as grocery shopping, cooking, and eating. Decreased food intake may result in an unhealthy diet, and in malnutrition, which is highly prevalent in patients with COPD. Malnutrition is known to negatively impact clinical outcome and quality of life.

Aims: In this qualitative study, we aimed to explore strategies used to overcome food-related challenges, ie, dietary resilience, and whether these led to a healthy diet. Furthermore, we aimed to identify the key themes of motivation for dietary resilience in patients with severe COPD. Methods: In October 2015 to April 2016, 12 patients with severe COPD starting a pulmonary rehabilitation program were interviewed. Qualitative description and thematic analysis were performed.

Results: All participants mentioned the use of strategies to overcome challenges. Key themes of motivation for dietary resilience were identified as "wanting to be as healthy as possible", "staying independent", and "promoting a sense of continuity and duty". Two out of 12 participants met the criteria for a healthy diet.

Conclusion: Our study showed a variety of motivational factors and strategies reported by patients with severe COPD to overcome food-related challenges. However, the majority $(n=10)$ of the participants did not meet the criteria for a healthy diet. The identified key themes can be used to develop education to support patients with severe COPD to improve their diet.

Keywords: chronic obstructive pulmonary disease, malnutrition, diet, resilience, health behavior, qualitative

\section{Introduction}

Patients with COPD experience several disabling symptoms, such as breathlessness and fatigue, that may impact food-related activities of daily living such as grocery shopping, cooking, and eating meals. ${ }^{1}$ Decreased food intake may result in an unhealthy/ unbalanced diet. It could also lead to malnutrition, which is highly prevalent in patients with COPD, varying from $11 \%$ to $62 \%$, largely depending on the disease stage..$^{2,3}$ Malnutrition is known to negatively impact clinical outcome and quality of life. ${ }^{4}$ Dry mouth, stomach ache, or other pains are reported to affect appetite and may impair food intake in this specific patient population. ${ }^{5}$ Other reported food-related challenges are limited social support and financial resources, as well as reduced motivation and insufficient knowledge about the importance of nutrition in COPD. ${ }^{1}$

The importance of adequate nutrition in patients with COPD is well-established. In 2014, the European Respiratory Society published a statement that a healthy/ well-balanced diet is beneficial to all patients with COPD, not only for its potential pulmonary benefits, but also for its proven benefits in terms of metabolic and cardiovascular risk. ${ }^{6}$ Aiming to achieve a healthy diet by developing strategies for food-related submit your manuscript Dovepress f 1 in 0 http://dx.doi.org/10.2147/COPD.S|5|720 cC. hereby accept the Terms. Non-commercial uses of the work are permitted without any further permission from Dove Medical Press Limited, provided the work is properly attributed. For permission for commercial use of this work, please see paragraphs 4.2 and 5 of our Terms (https://www.dovepress.com/terms.php). 
challenges is a process that has been described as "dietary resilience". 7 Generally, resilience has been described as "a dynamic process encompassing positive adaptation within the context of significant adversity". ${ }^{8}$ According to the transtheoretical model of behavior change, the development of strategies is a vital supplementation to the belief that one can attain a goal, self-efficacy, in order to actually adapt certain healthy behavior. ${ }^{9,10}$ Dietary resilience may therefore be considered a necessary step in addressing food-related challenges.

To prevent malnutrition in this patient population, it is important to explore strategies and motivational resources that patients with COPD use to overcome challenges for healthy diet. If we know how and why strategies are applied by a patient, this might be useful to help another patient. This knowledge could enhance further development of professional nutritional care for patients with COPD. In this study, we aimed to explore the strategies used by patients with severe COPD in their habitual situation to overcome specific food-related challenges, and whether these strategies were successful in terms of achieving a healthy diet. Furthermore, we aimed to identify the key themes of motivation for the process of dietary resilience in patients with severe COPD.

\section{Methods}

\section{Study sample}

From October 2015 to April 2016, a sample of patients with severe COPD participating in a quantitative study that aimed to explore relations between malnutrition, frailty, and disability were included in this qualitative study at the pulmonary rehabilitation ward of the University Medical Center Groningen (UMCG). Pulmonary rehabilitation is a:

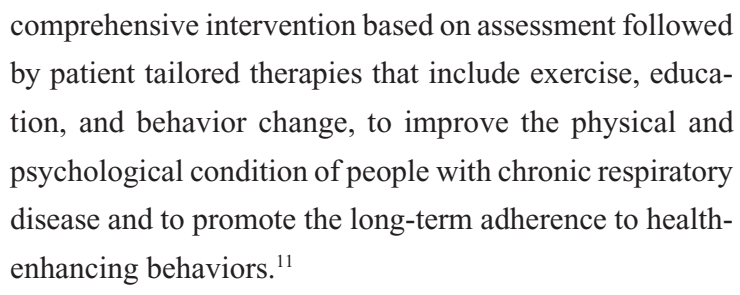

Inclusion criteria for the quantitative study were: aged $\geq 40$ years; able to understand and speak the Dutch language; diagnosed with COPD by a pulmonary physician and participating in the rehabilitation program; no severe cognitive disabilities reported in medical history; no palliative treatment; no wheel-chair dependency, no contraindication for physical exercise, no skin problems, and no pacemaker.
Patients were consecutively selected for inclusion in this qualitative sub-study, if they experienced two or more of the following risk factors that can lead to nutritional vulnerability: lack of appetite, dry mouth, pain, shortness of breath, or living alone, and expressed interest in participating in an interview. The significance of these selected risk factors was to distinguish between patients who are likely to experience food-related challenges and consequently are able to show dietary resilience, and patients who may not experience challenges. The risk factors were adapted from the literature and were based on the baseline demographic and medical characteristics, as well as results from a pilot study. ${ }^{5,7,12}$ For that pilot study, six selected patients with severe COPD admitted to the rehabilitation ward were interviewed.

Age, body mass index (BMI), Hospital Anxiety and Depression Scale (HADS) data, and spirometry results were retrieved from the participants' medical records and their research record of the quantitative study. Nutritional status was assessed by using the Dutch version 3.7 of the Scored Patient-Generated Subjective Global Assessment (PG-SGA@ FD Ottery 2005, 2006, 2015) with permission of the copyright holder. ${ }^{13}$ These variables were used to describe the sub-sample.

Dietary intake was determined by the 24-hour recall method, 1-2 weeks before the interview. A research dietitian completed this assessment and analyzed these data by hand for food group intake. A trained undergraduate student in nutrition and dietetics checked and confirmed this analysis. Healthy diet was defined as an intake of $80 \%$ of the age- and gender-specific recommendations in the Dutch Nutritional Guidelines 2011, ${ }^{14}$ for at least five out of the six major food groups, ie, fruit; bread; cheese and milk; meat, fish, chicken, egg or vegetarian meat substitute; potatoes, pasta, or leguminous plants; and vegetables.

The Medical Ethical Committee of the UMCG gave permission to conduct this study according to the Dutch law regarding patient-based medical research obligation (reference 2014/432). Written informed consent was obtained from each patient. Patient data were processed and electronically stored according to the Declaration of Helsinki - ethical principles for medical research involving human subjects. ${ }^{19}$ This study was registered in the Dutch Trial Register ("Nederlands Trial Register") with registration number NTR5107.

\section{Study design}

Qualitative description was chosen as the method for collecting and analyzing results. The purpose of qualitative description is to describe the interviewee's experiences and thematically summarize interview or other qualitative data to 
provide an understanding. ${ }^{15-17}$ As interviews were short (30 to 45 minutes) and conducted only once during a clinic visit, this method was considered feasible and sufficient to address the research questions. One-on-one, face-to-face interviews were conducted when participants entered the in- or out-patient rehabilitation program. Interviews were completed by one trained investigator and digitally recorded for transcription. Questions focused on the participants' food-related experiences and were based on a topic list (available upon request from first author). Primary questions and prompts were: "Can you tell you me how you go about your grocery shopping, food preparation, and having your meal?", "Do you experience difficulties with these activities?", "Have you found ways to deal with [these food-related] obstacles?", "Why did you try to find solutions?", and "How important is it for you to eat healthily and why?". Based on the model developed by Vesnaver et al, ${ }^{7}$ a deductive conceptual model (Figure 1) was created during a pilot study that was conducted from February 2015 to June 2015 to develop a topic list for the COPD-specific setting. In the pilot study, primary questions and prompts were tested, and adapted accordingly, for their quality in encouraging patients to elaborate and reflect on their food-related activities. The topic list was reviewed and elaborated upon by three experts from the pulmonary rehabilitation ward, a psychologist, a dietitian, and a physician assistant, after which the topic list was refined.

\section{Coding and analyses}

All interviews were transcribed and checked by a research dietitian and an undergraduate student in applied psychology. Braun and Clarke's six steps for qualitative descriptive

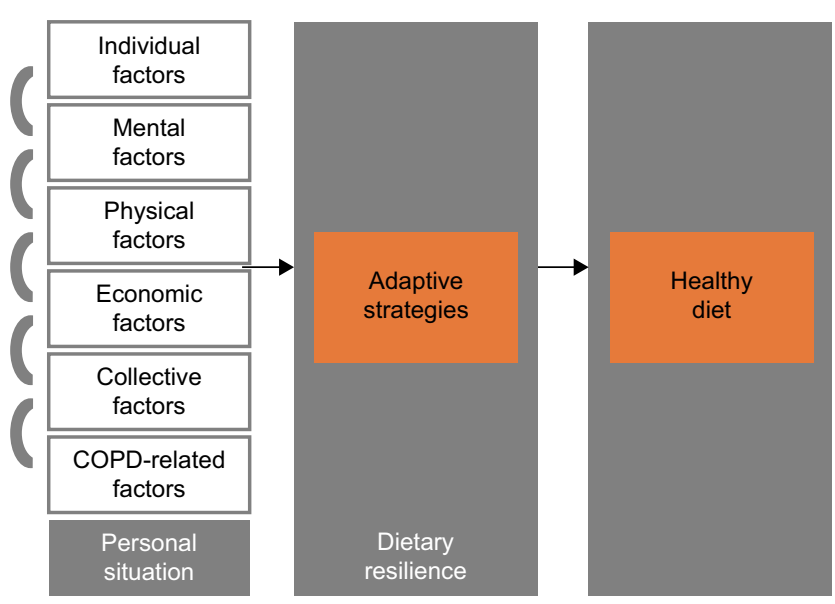

Figure I Deductive conceptual model in patients with COPD.

Note: Adapted from Appetite, 2012;58(2), Vesnaver E, Keller $\mathrm{HH}$, Payette $\mathrm{H}$, Shatenstein B. Dietary resilience as described by older community-dwelling adults from the NuAge study "if there is a will -there is a way!" 730-738. Copyright 2012, with permission from Elsevier. thematic analysis were completed. These steps consist of familiarizing with the data, generating initial codes, searching for themes, reviewing themes, defining and naming themes, and production of the report. ${ }^{18}$ Both deductive codes, ie, codes derived from the empirical research on the factors known to potentially influence food intake in this patient population, and inductive codes, ie, derived from the data, were systematically assigned, compared, and verified. Codes were arranged into possible themes through searching for "relations". By collating these initial themes to the coded data and to the complete interviews, a map of themes was created. Two co-authors confirmed these themes and provided insights to conduct further analysis. Key themes arose predominantly by inductive reasoning and through further discussion. Preliminary results were discussed with other researchers from the Research Group Healthy Ageing, Allied Health Care and Nursing to enhance in-depth analysis and reflection. Memos, diagrams, and initial results were presented and reviewed by authors for their input, facilitating logical coherent concept development. Recruitment of new participants was closed when no new themes were arising from the collected data; thus, emergence of new themes was used as saturation criterion. Participant numbers (\#) are used to discriminate between participants. Quotations used to support the key themes were forward translated from Dutch into English for publication, and these translations were carried out by two different authors.

Descriptive analyses of the sample included proportions for categorical variables. Numerical variables were presented as mean \pm SD for normally distributed variables, and as median with interquartile range for skewed variables. Normality was tested by the Shapiro-Wilk test. Two-tailed $P$-values were used, and significance was set at $P<0.05$. Data were analyzed using IBM SPSS version 23.0 (IBM Corporation, Armonk, NY, USA).

\section{Findings}

Between November 2015 and March 2016, 12 patients with COPD were interviewed for 30-45 minutes. Participants' characteristics are shown in Table 1. Mean age (years) was $59.2 \pm 8.3$ and eight participants were female. Seven participants were living alone. Two of 12 participants met the criteria for a healthy diet. Seven participants were well nourished (PG-SGA stage A). Mean BMI was 25.1 \pm 6.3 .

\section{Reported food-related challenges and strategies}

All participants reported challenges with grocery shopping, cooking, and/or eating. Grocery shopping was influenced by 
Table I Characteristics of the study sample $(n=12)$

\begin{tabular}{|c|c|c|}
\hline & $\mathbf{N}$ & $\begin{array}{l}\text { Mean }\left( \pm S^{a}\right) \text { or } \\
\text { median }\left(I Q R^{b}\right)\end{array}$ \\
\hline \multicolumn{3}{|l|}{ Gender } \\
\hline Male & 4 & \\
\hline Female & 8 & \\
\hline Age, years & & $59.2 \pm 8.3$ \\
\hline BMI, kg/m² & & $25.1 \pm 6.3$ \\
\hline \multicolumn{3}{|l|}{ Risk factors for impaired food intake } \\
\hline Living alone & 7 & \\
\hline Dry mouth & 9 & \\
\hline Chest tightness & 12 & \\
\hline Pain & 6 & \\
\hline Lack of appetite & 4 & \\
\hline Healthy diet ${ }^{c}$ & 2 & \\
\hline Nutritional status & & \\
\hline PG-SGA ${ }^{d}$ stage $A$ : well nourished & 7 & \\
\hline $\begin{array}{l}\text { PG-SGA stage B: moderate or suspected } \\
\text { malnutrition }\end{array}$ & 4 & \\
\hline PG-SGA stage C: severely malnourished & I & \\
\hline HADS $^{e}$ depression range & & 3 (IQR: I to 5.5 ) \\
\hline \multicolumn{3}{|l|}{ (0-2I points) } \\
\hline$\geq 8$ (possible or suspected depression) & I & \\
\hline HADS anxiety range (0-2I points) & & 3.5 (IQR: I.3 to 5.8 ) \\
\hline $\begin{array}{l}\geq 8 \text { (possible or suspected anxiety } \\
\text { disorder) }\end{array}$ & I & \\
\hline \multicolumn{3}{|l|}{ Comorbidities } \\
\hline Diabetes mellitus & I & \\
\hline Vascular disease $^{f}$ & 3 & \\
\hline Cardiac arrhythmia & 2 & \\
\hline Arthrosis of the hip & I & \\
\hline \multicolumn{3}{|l|}{ Smoking status } \\
\hline Smoking & 2 & \\
\hline Quit smoking & 10 & \\
\hline \multicolumn{3}{|l|}{ Spirometry } \\
\hline $\mathrm{FEV}_{1}(\mathrm{~L})$ & & 0.8 (IQR: 0.6 to I.5) \\
\hline $\mathrm{FEV}_{1}(\%$ predicted $)$ & & 29.5 (IQR: 22.0 to 57.3 ) \\
\hline $\mathrm{FEV}_{1} / \mathrm{FVC}$ ratio (\%) & & 34.5 (IQR: 26.0 to 48.3 ) \\
\hline \multicolumn{3}{|l|}{ COPD } \\
\hline GOLD 2 moderate & 3 & \\
\hline GOLD 3 severe & 3 & \\
\hline GOLD 4 very severe & 6 & \\
\hline
\end{tabular}

Notes: aStandard deviation. ${ }^{\circ} \mathrm{Q} Q \mathrm{R}$. 'Defined as an intake of $80 \%$ of the age and gender specific recommendations in the Dutch Nutritional Guidelines 201 I (14), for at least 5 out of the 6 major food groups. 'Scored PG-SGA (PG-SGAC); FD Ottery 2005, 2006, 2015). eHADS. 'Vascular disease: coronary artery disease, peripheral artery disease, transient ischemic attack. ${ }^{8}$ Disease classification according to the GOLD.

Abbreviations: IQR, interquartile range; BMI, body mass index; PG-SGA, PatientGenerated Subjective Global Assessment; HADS, Hospital Anxiety and Depression Scale; $\mathrm{FEV}_{1}$, forced expiratory volume in the first second; FVC, forced vital capacity; GOLD, Global Initiative for Chronic Obstructive Lung Disease.

COPD specific problems of chest tightness, weather conditions (hot, cold, windy, or misty), and lack of energy:

Grocery shopping calls for an extreme effort, so I have to take it easy, to not become short of breath. [\#5, Global Initiative for Chronic Obstructive Lung Disease (GOLD) 4, normal weight]

Additionally, the following non-specific challenges were also mentioned for grocery shopping: immobility, being overweight, limited financial resources, lack of physical strength, and nervousness. The main challenge reported for cooking was chest tightness, caused by cooking steam:

I buy ready-made meals, because I cannot breathe due to all the steam when I'm cooking. [\#12, GOLD 4, underweight]

Immobility was also a challenge for cooking, as well as the adverse influence of smell on appetite and lack of energy. Challenges described for eating were chest tightness; fatigue; lack of appetite, sometimes due to the smell of cooked food; dry mouth; and early satiation. Loss of partner and emotional stress were also non-COPD related challenges with eating, as stated by participant \#1 (GOLD 3, obese): "After my wife died, I thought I would never want to eat again." Participants who were mourning did not have higher HADS scores than those who were not mourning. Comorbidities were not reported as challenges for eating.

All participants in our study mentioned the use of strategies to deal with these challenges (Table 2). Eight participants were motivated to attain a healthy diet out of a desire for independence; to improve life satisfaction; out of responsibility toward others; nurturance; and/or physical health. The key themes representing these motivations were "wanting to be as healthy as possible", "staying independent", and "promoting a sense of continuity and duty". The participants maintaining a healthy diet ( $\mathrm{n}=2$ ) made use of self-discipline to overcome their lack of appetite and reported more than one motivation for eating as healthily as possible. They also made use of more strategies than participants who also reported more than one motivation for eating healthily, but did not achieve a healthy diet $(n=3)$. The remaining participants overall reported fewer motivations and used fewer strategies to overcome challenges.

\section{Key theme I: wanting to be as healthy as possible}

Physical health issues were frequently mentioned as motivation for developing strategies to eat healthily, with some $(\mathrm{n}=2)$ reporting multiple health-related reasons. When specifically asked, none reported a fear of adverse course of COPD, but rather specific adverse nutrition-related outcomes, such as a negative effect on body composition and physical functioning. Participants mentioned explicitly that eating healthily helped them to improve their immune status and avoid potentially devastating infections:

[...] I know that if I would continue to have these infections, I would not live much longer. [\#7, GOLD 2, obese] 
Table 2 Food-related challenges and strategies reported by patients with COPD

\begin{tabular}{|c|c|}
\hline Challenges & Strategies \\
\hline \multicolumn{2}{|l|}{ Grocery shopping } \\
\hline Chest tightness $(n=6)$ & Getting help from others \\
\hline Lack of energy $(n=3)$ & Adjust to a slower pace \\
\hline Lack of physical strength & Use of a car/E-bike \\
\hline$(n=1)$ & Use of a trolley/cart \\
\hline Being overweight $(n=l)$ & Choose particular point in time to \\
\hline Nervousness $(n=I)$ & avoid crowded conditions \\
\hline \multicolumn{2}{|l|}{ Windy weather $(n=l)$} \\
\hline \multicolumn{2}{|l|}{ Hot weather $(n=I)$} \\
\hline \multicolumn{2}{|l|}{ Misty weather $(n=I)$} \\
\hline \multicolumn{2}{|l|}{ Cold weather $(n=I)$} \\
\hline \multicolumn{2}{|l|}{ Limited financial } \\
\hline \multicolumn{2}{|l|}{ resources $(n=2)$} \\
\hline \multicolumn{2}{|l|}{ Cooking } \\
\hline Steam from cooking $(n=5)$ & Getting help from others \\
\hline Smell of food $(n=l)$ & Air-refreshing measures like opening \\
\hline \multirow[t]{10}{*}{ Lack of energy $(n=3)$} & all windows or use of a cooking hood \\
\hline & $\begin{array}{l}\text { Specific choice of food (with regard to } \\
\text { time to cook or smell) }\end{array}$ \\
\hline & Adjust to a slower pace \\
\hline & Eating fast food now and then \\
\hline & One-pan dish \\
\hline & Prepare food for several days so the \\
\hline & effort in the next days is limited \\
\hline & Ready-made meals \\
\hline & Hairdresser chair to easily move \\
\hline & around the kitchen, while sitting \\
\hline \multicolumn{2}{|l|}{ Eating } \\
\hline Loss of partner $(n=2)$ & Creating a pleasant atmosphere at the \\
\hline Stress $(n=3)$ & dinner table with music and/or reading \\
\hline Smell of cooked food & $\begin{array}{l}\text { Search for companion to have } \\
\text { dinner with }\end{array}$ \\
\hline $\begin{array}{l}(n=1) \\
\text { Dry mouth }(n=I)\end{array}$ & $\begin{array}{l}\text { dinner with } \\
\text { Look ahead to the future }\end{array}$ \\
\hline Chest tightness $(n=4)$ & Use of "meal boxes" \\
\hline Fatigue $(n=4)$ & Drinking with meal \\
\hline Lack of appetite $(n=3)$ & Breathing techniques \\
\hline Early satiation $(n=1)$ & Adjust the amount of activity before \\
\hline \multirow[t]{11}{*}{ Eating too fast $(n=1)$} & eating \\
\hline & Smaller portions and spreading \\
\hline & of meals \\
\hline & Self-discipline by talking to one-self in \\
\hline & $\begin{array}{l}\text { a firm way } \\
\text { Implementation of regularity }\end{array}$ \\
\hline & Implementation of regularity \\
\hline & Being encouraged by partner \\
\hline & Alternatives like liquid foods or \\
\hline & specific choice of food \\
\hline & Being encouraged by children \\
\hline & Taking extra time \\
\hline
\end{tabular}

Concerns about weight loss were also reported by participants, who knew the possible consequences to their health and quality of life:

If you lose weight you become weak and may need to be fed by a tube $[\ldots]$ that's no fun. [\#4, GOLD 4, overweight]
Specific loss of muscle mass was also described:

I think it is important for everyone, but for me it is of great importance that I eat the good stuff, so that I get proteins for my muscles. [\#3, GOLD 2, normal weight]

These motivations could overpower poor appetite and "not feeling like eating":

I just have to eat [...] so that the body can perform. [\#6, GOLD 4, underweight]

In addition to these specific perceived reasons to promote quality food intake, general health improvement was also a motivational factor for developing strategies:

It just helps me with my COPD [...] to always eat as health-

ily as possible. [\#9, GOLD 3, normal weight]

Yet, some $(n=4)$ participants indicated no evident awareness of the significance of their diet with regard to health. For example, one participant showed some ambivalence about eating healthfully:

Eating is not important to me but everyone has to eat. [\#6, GOLD 4, underweight]

while another stated that:

COPD is not curable, there is nothing we can do about that.

[\#11, GOLD 3, normal weight]

and another said:

I only eat when I think I will enjoy it [...] I do not necessarily eat healthily. [\#2, GOLD 4, normal weight]

Thus, physical health was a motivational factor for some $(n=7)$ participants but not all, suggesting that additional motivations are used to influence food choice. These other motivations described by participants are provided in the next section.

\section{Key theme 2: staying independent}

Participants described independence as "freedom of aid from others", and saw this as an important condition for all activities of daily living, including cooking and buying food. This motivation for eating well was primarily voiced by participants who were living alone. Feeling the need to "do it yourself" was enhanced by thoughts of not depending on others for your own good:

[...] why would you, if you can do it yourself, ask anyone else? If it's not really necessary, I think this would be taking advantage of your position. [\#6, GOLD 4, underweight] 
Another participant stated:

My children have their own lives, and I have to live mine [...] things I am able to do myself, I must do myself, that is how I feel. [\#9, GOLD 3, normal weight]

In addition, participants did not want to become a burden for others and reported feeling very uncomfortable about asking for help:

Everyone is busy, imagine that you need to ask someone every day if they would be so kind to help [...] I consider that dreadful, but sometimes you just have to ask. [\#8, GOLD 2, overweight]

and

I don't want to do this to my daughter, to ask her to do my grocery shopping, she has her children that keep her busy.

[\#11, GOLD 3, normal weight]

These statements demonstrate that participants may have ethical objections toward asking for help from their family and friends, regardless of the COPD diagnosis. Sticking to a "principle" was another reason for wanting to stay independent. For example, a participant did not want to give up on a certain social position:

I do not ask people for help, people ask me for help.

[\#12, GOLD 4, underweight]

Another participant reported being afraid that the necessity of help from others would increase over time and used this as a reason for not asking for too much help. He stated it was no problem for him to ask family, friends or neighbors for a small favor, but was being careful about doing this too often:

If I ask my friends, family or neighbors every time [...] then this will happen more and more, it is very important to me to be able to do this myself. [\#5, GOLD 4, normal weight]

These reported objections to asking for help are an impetus for participants to develop strategies, including overcoming grocery shopping and cooking challenges, to stay independent.

\section{Key theme 3: promoting a sense of continuity and duty}

Other intrinsic reasons mentioned by the participants suggested that a continuity of feelings or beliefs was also motivation for food choice. For example, a participant described a decrease in feelings of life satisfaction, because of functional and conditional limitations due to being overweight along with COPD:

[...] I felt that my joy of life was fading. Every year I went on holiday with a friend, and this year I told her I cannot go because I cannot walk the distance, so there is no point in going on holiday. [\#7, GOLD 2, obese]

Eating healthily was also motivated by experience and habit, as it was what your parents taught you:

It is the upbringing I had, my mother used to be a nurse and she taught me to keep eating even when you are severely ill. [\#5, GOLD 4, normal weight]

A strong feeling of responsibility for others was also reported as a motivational factor:

I want to live some extra years because I look after my sister and I feel that I cannot assign this task to anyone else. [\#7, GOLD 2, obese]

Although consistent with the prior theme, a "sense of continuity and duty" had an emotional motivation outside of the individual and their health experience. These emotionally inspired reasons were strong motivators to overcome foodrelated challenges for these participants. Yet, none of the participants reported any feelings of pressure from family or health care professionals as a reason for developing strategies for eating healthily. However, support from loved ones, either partners or children, was mentioned in the context of "what is keeping you on track" eating healthily and was reported to be an influential strategy.

\section{Discussion}

In this study, we identified three key themes that stimulate dietary resilience in patients with severe COPD: "wanting to be as healthy as possible", "staying independent", and "promoting a sense of continuity and duty". This study showed that most $(n=8)$ participants were motivated to develop strategies and applied strategies to overcome food-related challenges. Although a wide range of strategies to support food intake were applied, most participants $(n=10)$ did not achieve a healthy diet.

Only two out of 12 participants in our study met the criteria for a healthy diet. This is in line with previous studies showing that it is difficult for patients with COPD to achieve a healthy diet. A recent study on diet quality in 121 stable COPD patients found that only $3 \%-6 \%$ of the study population could be considered to have "good diet quality". ${ }^{20}$ Another study found that most older patients with COPD (mean age $74 \pm 7$ years) do not 
meet energy requirements (52\%) or Recommended Dietary Allowances for various other nutrients (75\%). ${ }^{21}$

In our sample, only participants who had at least two key themes of motivation were able to achieve a healthy diet. The number of strategies that participants apply may add to the level of success in achieving a healthy diet, as the two participants who achieved a healthy diet both used more strategies than all other participants. These findings suggest that multiple motivations to eat well and application of a large number of strategies support healthy eating. In previous research on dietary resilience in healthy older people, it was found that food-related motivation and understanding the relevance of a healthy diet were necessary conditions in order to achieve a healthy diet, but were found not to be sufficient, implying a need for effective strategies. ${ }^{7}$ In a previous study on dietary intake in patients with COPD, it was reported that emotional status and specific knowledge about food groups impacted dietary intake. ${ }^{1}$ However, we did not assess affect or knowledge of a healthy diet in our patient sample.

This is the first study to explore dietary resilience in patients with severe COPD and the study had some limitations that need to be discussed. First, due to the qualitative nature of this study, results would typically not be generalizable. Since our participants were patients with severe COPD in a tertiary rehabilitation center that provides advanced specialized care, we do not know to which extent the participants in our sample and their key themes are representative of patients with COPD in general. The findings from our study, however, could be used to develop and assess interventions aimed at prevention and/or solving food-related problems in other patients with severe COPD. Second, the 24-hour recall is a method to assess actual intake and may not be representative of usual dietary habits. ${ }^{22}$ However, our participants indicated that their reported daily intake was stable over time.

Knowledge of the strategies used by our patient sample can create new possibilities for the professional nutritional support of patients with severe COPD. For example, the strategies described in Table 2 may be used in clinical practice as ideas for potential ways to support healthy intake. The identified motivations for improving food intake reported by our participants can also be used in clinical practice. Understanding of the key themes and the underlying motivations may help health care professionals with their counseling of patients, to stimulate the use of strategies for food-related challenges in order to achieve a healthy diet. By using motivational interviewing, the motivations/key themes that were reported by our participants could be used to search for unspoken needs. Current theory of health promotion, eg, as used in the context of smoking cessation and improving physical activity, relies on the concept of self-efficacy and is based on the well-established trans-theoretical model of "Stages of Change" ${ }^{9,10}$ Motivational interviewing has been shown to be effective in stimulating treatment compliance and self-management in patients reporting non-motivational factors for a healthy behavior. ${ }^{23}$

In conclusion, our exploratory study showed that patients with severe COPD at the start of pulmonary rehabilitation apply many different strategies for food-related challenges. The key themes of motivation for dietary resilience by these participants were "wanting to be as healthy as possible", "staying independent", and "promoting a sense of continuity and duty". However, the majority $(\mathrm{n}=10)$ of participants with severe COPD starting the rehabilitation program did not meet the criteria for a healthy diet. We do not know whether participants meet these criteria at the end of the rehabilitation program nor whether they have familiarized themselves with additional strategies. This study was a "first step" and future research needs to address these remaining questions. Furthermore, additional research needs to corroborate the key themes in a more diverse group of patients with COPD, as well as to study how these motivational factors could stimulate achieving a healthy diet.

\section{Acknowledgments}

We would like to thank Niels de Voogd, Janneke Dilling, Leanda Brinkman, and Petra Goedemoed of the pulmonary rehabilitation ward of the UMCG, and Noor de Vink, Manon Westra, and Marije Rolsma, students at the Hanze University of Applied Sciences for their valuable contribution to this study.

The abstract of this paper was presented at the 2016 ESPEN Congress as a poster presentation with interim findings. The poster's abstract was published in "Abstracts of 38th ESPEN Congress in Copenhagen, Denmark, 17-20 September 2016" in Clinical Nutrition, 2016;35 Supplement 1:S85-S86.

\section{Disclosure}

$\mathrm{H}$ van der Vaart received a personal fee from Vertex outside the submitted work. The authors report no other conflicts of interest in this work.

\section{References}

1. Shalit N, Tierney A, Holland A, Miller B, Norris N, King S. Factors that influence dietary intake in adults with stable chronic obstructive pulmonary disease. Nutrition \& Dietetics. 2016;73(5):455-462.

2. Luo Y, Zhou L, Li Y, et al. Fat-free mass index for evaluating the nutritional status and disease severity in COPD. Respir Care. 2016; 61(5):680-688. 
3. Ng MG, Kon SS, Canavan JL, et al. Prevalence and effects of malnutrition in COPD patients referred for pulmonary rehabilitation. Eur Respir J. 2013;42:5107.

4. Rasheed S, Woods RT. Malnutrition and quality of life in older people: a systematic review and meta-analysis. Ageing Res Rev. 2013; 12(2):561-566.

5. Nordén J, Grönberg AM, Bosaeus I, et al. Nutrition impact symptoms and body composition in patients with COPD. Eur J Clin Nutr. 2015; 69(2):256-261.

6. Schols AM, Ferreira IM, Franssen FM, et al. Nutritional assessment and therapy in COPD: a European Respiratory Society statement. Eur Respir J. 2014;44(6):1504-1520.

7. Vesnaver E, Keller HH, Payette H, Shatenstein B. Dietary resilience as described by older community-dwelling adults from the NuAge study "if there is a will -there is a way!". Appetite. 2012;58(2):730-738.

8. Luthar SS, Cicchetti D, Becker B. The construct of resilience: a critical evaluation and guidelines for future work. Child Dev. 2000;71(3):543-562.

9. Bandura A. Self-efficacy: toward a unifying theory of behavioral change. Psychol Rev. 1977;84(2):191-215.

10. Prochaska JO, DiClemente CC. The transtheoretical approach. In: Norcross JC, Goldfries MR, editors. Handbook of Psychotherapy Integration. New York: Oxford University Press; 2005:147-171.

11. Spruit MA, Singh SJ, Garvey C, et al. An official American Thoracic Society/European Respiratory Society statement: key concepts and advances in pulmonary rehabilitation. Am J Respir Crit Care Med. 2013; 188(8):e13-e64.

12. Elsner RJ. Changes in eating behavior during the aging process. Eat Behav. 2002;3(1):15-43.

13. Sealy MJ, Hass U, Ottery FD, van der Schans CP, Roodenburg JLN, Jager-Wittenaar H. Translation and cultural adaptation of the Scored Patient-Generated Subjective Global Assessment: an interdisciplinary nutritional instrument appropriate for Dutch cancer patients. Cancer Nurs. Epub 2017 May 19.
14. Voedingscentrum. Richtlijnen Voedselkeuze. Den Haag: Stichting Voedingscentrum Nederland; 2011. Available from: http:// www.voedingscentrum.nl/Assets/Uploads/voedingscentrum/Documents/Professionals/Voedselvoorlichting/01_Richtlijnen\%20voedselkeuze\%20Voedingscentrum.pdf. Accessed February 23, 2018.

15. Sandelowski M. Whatever happened to qualitative description? Res Nurs Health. 2000;23(4):334-340.

16. Sandelowski M. What's in a name? Qualitative description revisited. Res Nurs Health. 2010;33(1):77-84.

17. Neergaard MA, Olesen F, Andersen RS, Sondergaard J. Qualitative description - the poor cousin of health research? BMC Med Res Methodol. 2009;9:52.

18. Braun V, Clarke V. Using thematic analysis in psychology. Qual Res Psychol. 2006;3(2):77-101.

19. wma.net [homepage on the internet]. Declaration of Helsinki. Ethical principles for medical research involving human subjects. World Medical Association; 2013. Available from: http://www.wma.net/ policies-post/wma-declaration-of-helsinki-ethical-principles-formedical-research-involving-human-subjects/. Accessed February 23, 2018.

20. Yazdanpanah L, Paknahad Z, Moosavi AJ, Maracy MR, Zaker MM. The relationship between different diet quality indices and severity of airflow obstruction among COPD patients. Med J Islam Repub Iran. 2016;30:380.

21. Laudisio A, Costanzo L, Di Gioia C, et al. Dietary intake of elderly outpatients with chronic obstructive pulmonary disease. Arch Gerontol Geriatr. 2016;64:75-81.

22. Gleason PM, Harris J, Sheean PM, Boushey CJ, Bruemmer B. Publishing nutrition research: validity, reliability, and diagnostic test assessment in nutrition-related research. J Am Diet Assoc. 2010;110(3):409-419.

23. Huber M, Knottnerus JA, Green L, et al. How should we define health? BMJ. 2011;343:d4163.
International Journal of COPD

\section{Publish your work in this journal}

The International Journal of COPD is an international, peer-reviewed journal of therapeutics and pharmacology focusing on concise rapid reporting of clinical studies and reviews in COPD. Special focus is given to the pathophysiological processes underlying the disease, intervention programs, patient focused education, and self management protocols.

\section{Dovepress}

This journal is indexed on PubMed Central, MedLine and CAS. The manuscript management system is completely online and includes a very quick and fair peer-review system, which is all easy to use. Visit http://www.dovepress.com/testimonials.php to read real quotes from published authors. 